\title{
De la contradicción a la alternativa: la teoría urbana crítica como base para una investigación empírica en torno al derecho a la vivienda en el Área Metropolitana de Bilbao
}

Ion Etxabe. Universidad Politécnica de Madrid, Madrid, España.

RESUMEN | Algunas de las contradicciones internas del capitalismo avanzado, señaladas durante sus últimas etapas, conforman una ciudad excluyente. La necesidad de realizar correcciones en el modelo urbano actual alcanza un considerable consenso, no obstante lo cual sus principales conflictos siguen siendo estructurales. El artículo pone a prueba una herramienta teórica que busca comprender el origen sistémico de dichos conflictos. Dicha herramienta ha sido diseñada con dos objetivos: por una parte, identificar las contradicciones generadas en procesos de gobernanza urbana, alimentadas, a la vez que superficialmente reguladas, por un sistema de 'gobernanza más allá del Estado’ desigual; y por otra, localizar alternativas, nacidas por y en contra de dichas contradicciones, que señalen posibles vías de salida. Tomando la vivienda como objeto y el Área Metropolitana de Bilbao como caso de estudio, se confirma la validez del instrumento y se señalan dos principales contradicciones del capitalismo en las que enmarcarlos, a partir de las cuales se apuntan algunas alternativas.

PALABRAS CLAVE | desigualdad social, geografía urbana, política urbana.

ABSTRACT | Cities of exclusion are the result of some of the internal contradictions of the last stages of advanced Capitalism. Although there is consensus on the need to make corrections to this current urban model, its main conflicts remain structural. This article tests a theoretical tool that seeks to understand the systemic origin of these conflicts. The tool was designed to both identify the contradictions generated in urban governance processes -nurtured and superficially regulated, by an unequal system of 'governance beyond the state'and to detect alternatives, born by and against these contradictions, that point to possible escapes. With housing as the object and the Metropolitan Area of Bilbao as the case study, this instrument's validity is confirmed. Finally, two main contradictions of Capitalism are highlighted, which suggest possible alternatives.

KEYWORDs | social inequality, urban geography, urban policy.

Recibido el 12 de septiembre de 2019, aprobado el 31 de diciembre de 2019.

E-mail: ionetxabe@gmail.com 


\section{Introducción}

Frente a posiciones más conformistas o pesimistas, la teoría crítica -con Marx como uno de sus principales hitos desde la crítica de la economía política- ha buscado no solo identificar las contradicciones internas del capitalismo, sino también señalar y explorar alternativas al mismo (Brenner, 2017, p. 237). Se trata de un posicionamiento mantenido por diferentes contribuciones al pensamiento marxista desde la geografía, la filosofía o el urbanismo (Harvey, 2014; Lefebvre, 2013; Marcuse, 1985), que han adoptado la teoría urbana crítica como instrumento para la transformación social. Aplicando este enfoque a la dimensión social de la vivienda -relativa a su función más básica, la del derecho a un alojamiento digno y adecuado-, el modelo de ciudad residencial del capitalismo avanzado se ha catalogado como sistémicamente excluyente (Madden \& Marcuse, 2018; Smith, 2015), a pesar de tratarse de un derecho humano fundamental. Recientes planteamientos sitúan este choque en un contexto de 'neoliberalismo realmente existente', dependiente de los marcos geográficos, sociales, históricos o regulatorios en los que se desarrolla, e internamente contradictorio (Brenner $\&$ Theodore, 2017). Como otros retos urbanos, la consecución del derecho a la vivienda depende de un contexto de 'gobernanza más allá del Estado', variable entendida como la apertura de la gestión de gobierno a agentes privados y civiles. Aparentemente horizontal y abierta, tal apertura esconde unas relaciones de fuerzas y capacidad de decisión desequilibradas (Swyngedouw, 2005), en un marco institucional de limitación y resistencia estructural al desarrollo de la gobernanza (Jessop, 2017, p. 140).

En torno al derecho a la vivienda en España destacan tres conflictos de urgente resolución:

- Las características del acceso económico en lo que respecta al desfase entre precios y capacidad de pago, y las exclusiones que genera esta situación (Inurrieta et al., 2013; Naredo, 2015; Vinuesa, 2013).

- El choque entre la evolución de las 'unidades de convivencia' y el predominio de unas tipologías residenciales diseñadas para formas de familia cada vez más minoritarias. Frente a conceptos habitualmente utilizados en estadística, como 'hogar' o 'familia', para referirse a las personas que habitan una vivienda, la 'unidad de convivencia' se define aquí como aquel conjunto de personas que cuenta con un deseo, proyecto o situación de convivencia en una vivienda o parte de la misma. Una situación que es fruto de las relaciones, familiares o no, existentes entre las personas que la conforman -en caso de ser más de una-, y no del verse forzadas a convivir por motivos económicos o de otra naturaleza. Esto desborda y complejiza las categorías de tamaño, estructura y familia, e incorpora otros niveles de convivencia, dinámicas laborales, biografías vitales o perfiles socioculturales (Guidotti \& Arroyo, 2004; Muxí, 2009; Paricio \& Sust, 2000).

- El contar con un parque infrautilizado como soporte de las unidades de convivencia, y ello tanto por la reproducción y el mantenimiento de esas tipologías, como por la coexistencia de viviendas usadas vacías, nuevas sin estrenar, y de 
personas sin posibilidad de acceder a una vivienda, tras una larga etapa de desa-

rrollismo (Azpiri, 1997; Naredo \& Montiel, 2011).

La hipótesis del artículo plantea que esta problemática se debe a que la supervivencia del modelo residencial español depende del mantenimiento de ciertas contradicciones sistémicas que son alimentadas, aunque superficialmente abordadas a través de regulaciones parciales, por una gobernanza parcialmente eficaz y desigual. Además, propone que del estudio y comprensión de estas contradicciones se podrán obtener pistas de posibles -o existentes- alternativas.

\section{Planteamiento}

El objetivo del artículo es doble: primero, aportar algo de luz y profundizar en las causas de una problemática residencial que perdura en España desde hace décadas bajo diferentes formas y evoluciones, pero que se ha tornado estructural. Segundo, poner a prueba una herramienta teórica de análisis que busca tanto identificar y comprender las contradicciones internas de fenómenos complejos propios del espacio social -entendido como instrumento y medio de reproducción del capitalismo como sistema dominante (Lefebvre, 2013, p. 86)-, como localizar posibles o existentes alternativas surgidas como reacción a ellas.

En esta perspectiva, se ha tomado como caso de estudio el Área Metropolitana de Bilbao (Амв), modelo de regeneración y reconversión urbana considerado en tanto referencia (Vegara, 1999; Vidarte, 2007), aunque cuestionado y desmitificado si se incorporan al análisis variables no relacionadas con la rentabilidad económica (Antolín et al., 2010; Rodríguez, 2002; Rodríguez et al., 2001; Swyngedouw et al., 2002; Vicario \& Rodríguez, 2005; Zubero, 2012).

Lo anterior deja en evidencia la pretendida naturalidad de un proceso de regeneración que es fundamentalmente político, social y económico (Smith, 2015, p. 267), y lleva a dudar del Амв como modelo global, contraponiendo a sus éxitos parciales otras realidades en forma de exclusión socioespacial bajo un modelo de ciudad neoliberal abierta al capital global.

La metodología enfrenta y relaciona algunos de los principales elementos que conforman los procesos de gobernanza urbana. Busca sustituir la interpretación de las problemáticas urbanas como una cuestión de agentes estancos con posiciones enfrentadas -gobierno, sociedad civil, iniciativa privada-, por una mirada que estudie la complejidad del espacio social y acepte la transversalidad de unas contradicciones identificables también en las acciones de los propios agentes. De manera abstracta y teórica, se plantea que, habiendo identificado una problemática concreta, la sociedad -considerada como conjunto de múltiples agentes, intereses y fuerzas, y no como un único sujeto autónomo (Jessop, 2017, p. 140)- responde con tres grandes fases (Figura 1): el debate y la definición de necesidades para establecer metas concretas; el diseńo y desarrollo de instrumentos para alcanzarlas; y la ejecución de dichos instrumentos. A todo ello, la herramienta enfrenta y da cuenta de una serie de condicionantes y obstáculos internos de la propia sociedad que producen un triple efecto: afectan negativamente a las tres fases, potencian e incluso causan la situación problemática de origen, y frenan la consecución de las metas establecidas. 
FIGURA I | Esquema conceptual de la generación de contradicciones en procesos de gobernanza urbana

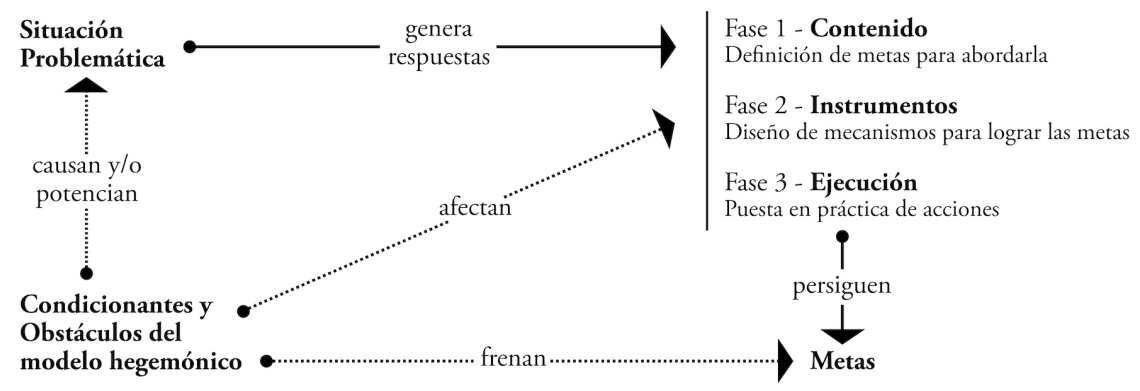

FUENTE: ELABORACIÓN PROPIA

\section{Resultados}

El apartado ilustra los elementos de la Figura 1 mediante un planteamiento cualitativo. Lo que sigue no es un mapeo exhaustivo, sino una mirada parcial, aunque profunda, sobre ejemplos locales del Амв - o de afección local- para ahondar en la gobernanza de esta región en materia de desarrollo de políticas de vivienda. En este sentido, el marco tomado es la revisión y definición que de este concepto hace Jessop (2017, p. 229), quien plantea los conceptos de gobernanza y complejidad como inseparables. Según recuerda el autor, el primero es un concepto que no cuenta con un núcleo jurídico-político o punto de referencia institucional relativamente fijo, y su práctica se relaciona no tanto -o no solo- con el gobierno, como con la política y la práctica política pública:

En términos generales, la gobernanza se refiere a mecanismos y estrategias de coordinación de cara a la interdependencia recíproca compleja entre agentes, organizaciones y sistemas funcionales operativamente autónomos. Las prácticas de gobernanza van desde la expansión de regímenes internacionales y supranacionales, pasando por asociaciones nacionales y regionales público-privadas, a redes de poder y de toma de decisiones más localizadas. (p. 230)

Además de la complejidad y diversidad de agentes, escalas y sistemas a los que hace mención, coordinación e interdependencia son dos aspectos de esta definición que centran especialmente el interés en el marco de este trabajo. Quedan así estrechamente ligadas, dado que el permanente cambio en el equilibrio de fuerzas generado por la interconexión e interrelación entre problemáticas, agentes, prácticas, escalas, instrumentos o tiempos requiere constantes esfuerzos de coordinación entre estos, y genera diferentes capacidades de toma de decisiones.

En cuanto al AMB, se trata de una región en torno a la cual, como en tantas otras, entran en juego no solo agentes y fuerzas propias de escalas locales, regionales, estatales, europeas y globales, sino también de ámbitos políticos, económicos, civiles o jurídicos muy diversos. Si bien el conocimiento de dicho entramado puede 
ayudar en la lectura del texto, no es este un aspecto fundamental. El desarrollo de la herramienta coloca la mirada en una serie de posicionamientos, acciones, posturas o discursos de muchos de esos agentes, suficientemente contextualizados para permitir la lectura y comprensión del trabajo. El centro de la investigación es la articulación, contradicción y relación de esas posturas y papeles y, por lo tanto, no es necesario conocer con detalle la estructura de dicho espacio social.

\section{Situación problemática y metas}

La problemática señalada se concreta en el AMB profundizando en las tres cuestiones apuntadas.

En primer lugar, existe una alta necesidad de vivienda, unida a una incapacidad económica de demanda. La crisis desatada en la década pasada ha incrementado la vulnerabilidad residencial de numerosos colectivos (Gobierno Vasco, 2013, p. 125; Open Data Euskadi, 2017). El mercado se resiste al ajuste a la demanda: el descenso de precios se estabiliza y estos suben en determinadas situaciones (Observatorio Vasco de la Vivienda, 2015, 2017a). La bajada de precios tras la explosión de la burbuja inmobiliaria es relativa, si se considera el gasto que se destina a la vivienda. Pero, por encima de dicho gasto, cuantificable y con frecuencia superior al límite consensuado del $30 \%$ de los ingresos de la unidad de convivencia, la convergencia de diferentes conflictos forma un contexto, cualitativo, de baja calidad de vida. Por ejemplo, la precarización del empleo y la disminución de ingresos en colectivos como el joven y el demandante de vivienda protegida (Consejo de la Juventud de Espańa, 2016; Gobierno Vasco, 2013, 2017), o la extendida dificultad de pago -tanto en régimen de propiedad como de alquiler, en vivienda pública y privada(Observatorio Vasco de la Vivienda, 2017b). Además, la definición institucional de 'necesidad' de vivienda exige la disponibilidad de ingresos, dejando fuera de las estadísticas a parte de los anteriores colectivos. ${ }^{1}$

Segundo, la oferta existente puede calificarse como de inadecuada, pero no de insuficiente. Las políticas públicas de vivienda de las últimas décadas han generado y/o facilitado un importante desfase entre "un desmedido e injustificado crecimiento inmobiliario" (Beltrán, 2009, p. 469) y una exclusión residencial estructural. La primacía de la propiedad como régimen de tenencia en un contexto de reducción de rentas expulsa del mercado a cada vez más personas. La oferta privada se orienta al lucro, y la oferta pública presenta dificultades para satisfacer la necesidad: a pesar de apostar por el alquiler protegido, "la conjunción de diversos factores ha hecho que los ambiciosos objetivos no siempre hayan podido cumplirse" (Gobierno Vasco, 2017, p. 33). Como en el resto de España, predominan tipologías residenciales que no responden a las necesidades de muchas unidades de convivencia, y las cifras de población y de viviendas existentes no reflejan desfase alguno en números globales; más bien, presentan una mayor capacidad potencial de alojamiento de un parque infrautilizado (Etxezarreta, 2010).

1 Según el Observatorio Vasco de la Vivienda, en la provincia de Bizkaia un 7,76\% de las unidades de convivencia presentaban situación de necesidad en 2015. Estas ascendían al 11,06\% al incluir unidades sin ingresos: de aquellas con necesidad, un 14,64\% tenía ingresos suficientes, un 55,53\% insuficientes o irregulares, y un 29,83\% no tenía ingreso alguno. 
Tercero, la ciudad existente necesita ser intervenida de manera integradora. Muchas de las herramientas y políticas de renovación y regeneración urbanas de los últimos ańos reproducen lógicas de creación de ciudad nueva sobre la existente. La alta dependencia de las operaciones respecto de la rentabilidad económica produce sustituciones de tejido urbano más que rehabilitación, con los consecuentes desplazamientos de población y rentas. Asimismo, los retos de comprender, cuantificar y gestionar el fenómeno de la vivienda vacía (Etxezarreta, 2010; Vinuesa, 2013, p. 13); de adaptar los edificios existentes, residenciales o no; de regular el creciente peso de la vivienda turística o de costear las transformaciones físicas de ese parque (Fumadó \& Paricio, 1999), no son pocos.

El peso del sistema urbanístico e inmobiliario residencial en la economía regional ha hecho que, desde la explosión de la burbuja inmobiliaria, la atención se haya centrado en el seguimiento de la promoción y compraventa, los precios y los puestos de trabajo perdidos; pero la verdadera problemática de fondo sigue sin resolverse, mientras la crisis financiera la recrudece (Etxezarreta, 2010, p. 5). Como reacción, puede identificarse en la sociedad la definición de tres metas orientadas a alterar un sistema dominante y excluyente centrado en el flujo y la acumulación de capital:

- La primera, ampliar y dignificar el acceso a la vivienda. Las dificultades existentes en parte de la población para demandar un alojamiento en el mercado libre, aceptar y costear una vivienda protegida o, contando con una vivienda habitual, destinar un porcentaje digno y asumible de las rentas de trabajo al pago de la misma sin incurrir en situaciones de vulnerabilidad, hacen de esta la principal meta.

- La segunda, intensificar la adecuación tipológica de las viviendas. El desfase entre las características espaciales habituales -tanto de las viviendas existentes como de las planificadas- y la evolución de los tipos de unidad de convivencia, plantea el reto de sacar de la esfera e iniciativa privada la adecuación del espacio doméstico, para incorporarla a las políticas públicas de vivienda.

- Por último, aprovechar la ciudad existente. La convergencia en el AMB de un territorio orográficamente complicado, un alto porcentaje de urbanización de los suelos aptos para ello, una ciudad con necesidad de ser actualizada, una población en estancamiento o muy ligero crecimiento y un modelo urbanístico estructuralmente expansionista, lleva a tomar el parque residencial heredado como soporte para la consecución de las dos metas anteriores.

\section{Fases de gobernanza}

La respuesta de la sociedad como conjunto heterogéneo ante una problemática puede enmarcarse en tres grandes fases teóricamente ordenadas, pero en realidad continuamente retroalimentadas. Esta comenzaría con la fase del Contenido: identificada la problemática, un proceso de gobernanza se iniciaría idealmente con la definición de las principales metas; los diversos agentes generan un contenido que, a priori, cuenta con un amplio consenso (Tabla 1). A esta le seguiría la fase de los Instrumentos: por promoción propia o por la ratificación de otros superiores -estatales o internacionales-, existe una serie de herramientas de diversa naturaleza y escala que buscan 
poner en práctica buena parte del contenido generado (Tabla 2). Finalmente, llegaría la Ejecución: esta es identificada como parcial, resultado de un proceso de gobernanza limitado y condicionado por los conflictos que a continuación se desarrollan. $\mathrm{Su}$ reflejo se ha podido ver en la situación problemática arriba expuesta. 


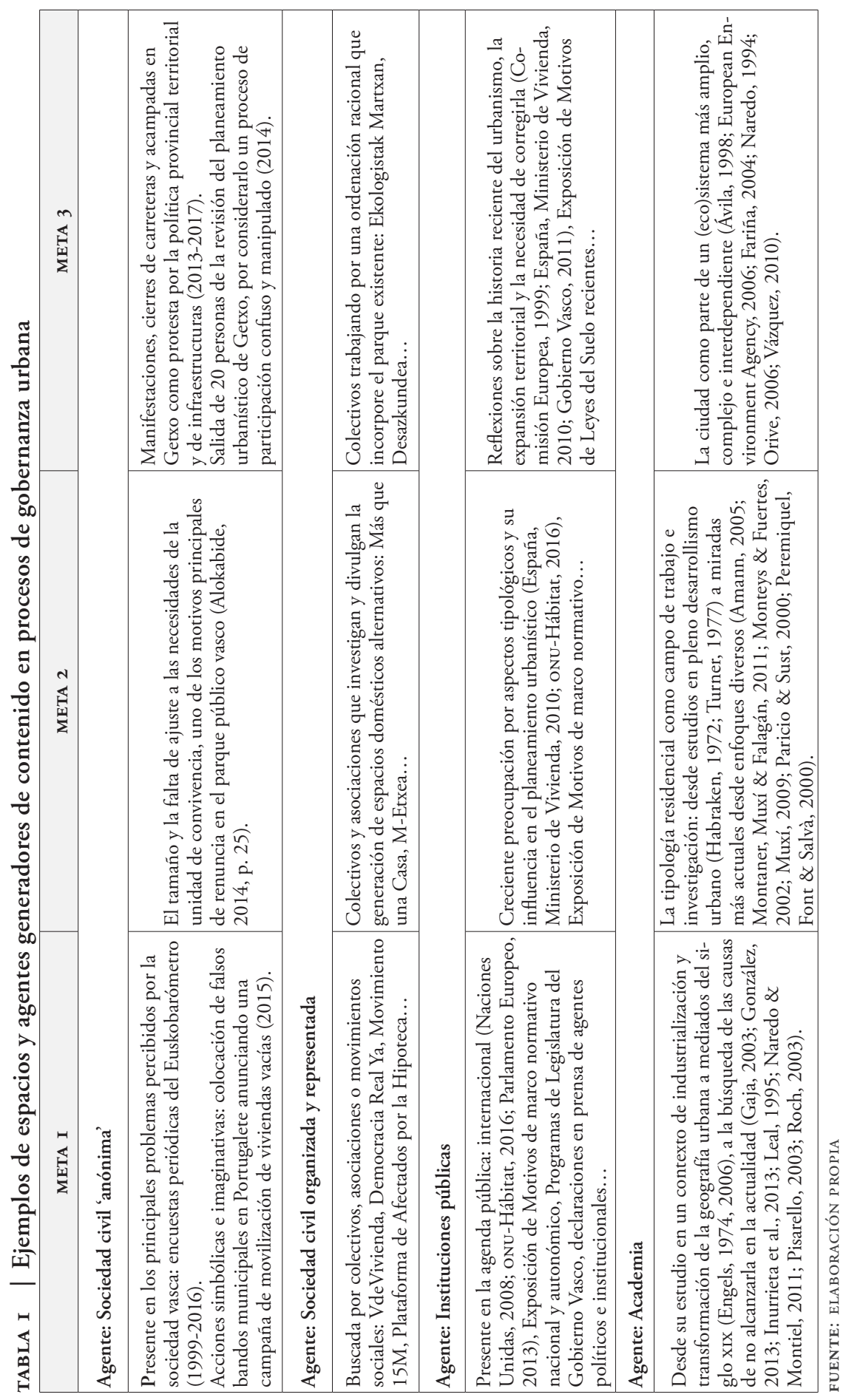




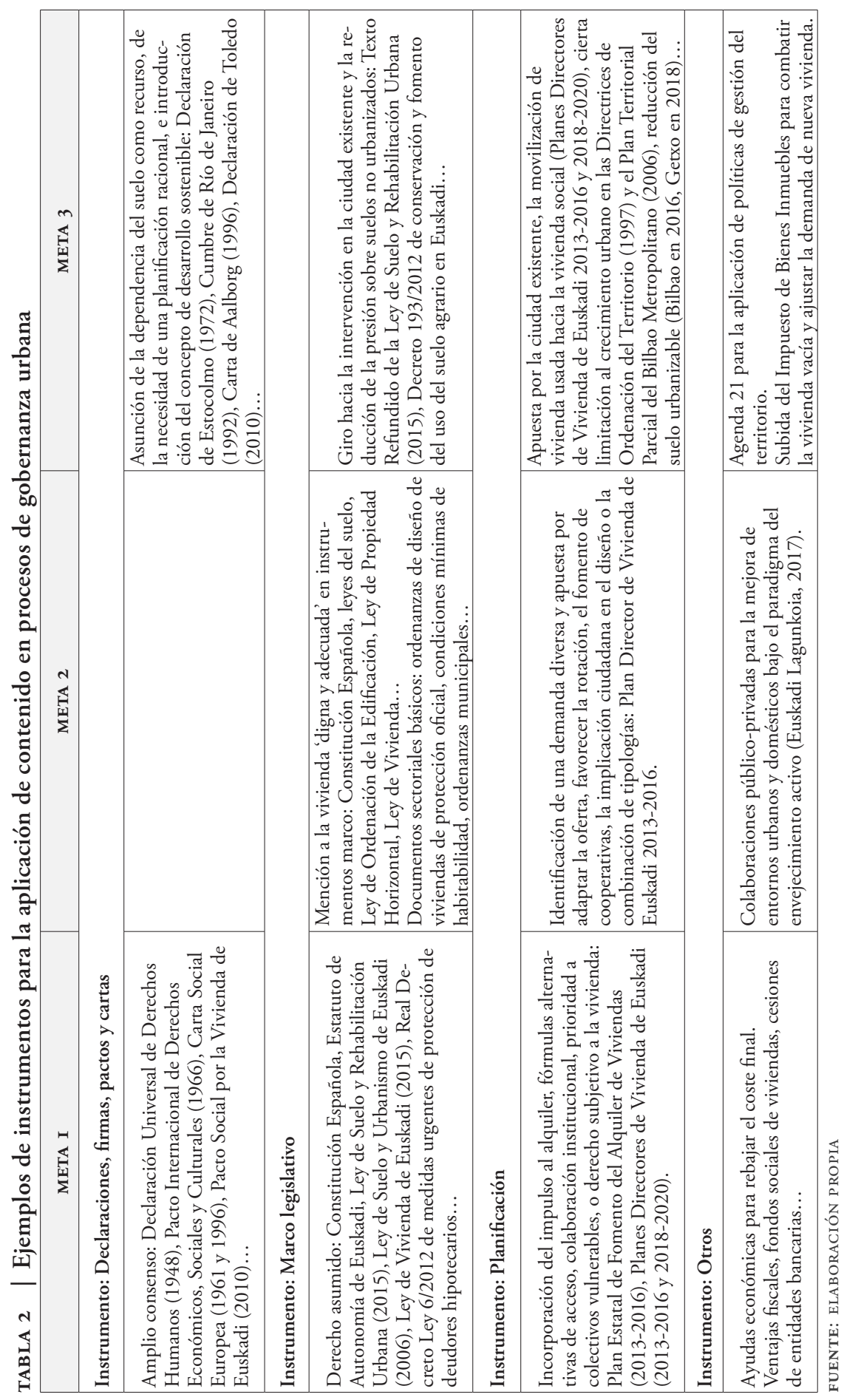




\section{Condicionantes y Obstáculos}

Como contrapunto a lo anterior, existe una serie de fenómenos que afectan negativamente las tres fases de gobernanza planteadas. Dichos fenómenos van desde inercias y construcciones sociales más o menos conscientes, a intereses y presiones sectoriales, pasando por carencias de fondo en la definición de metas, e instrumentos limitados en origen o sin utilizarse en toda su capacidad. Muchos de estos obstáculos son propios de una visión hegemónica que favorece consensos entre ciertos agentes (enfrentados, sin embargo, en otros asuntos): aquella que toma la ciudad como "máquina de crecimiento" y fuente de generación de rentas (Logan \& Molotch, 1987, p. 50). Así, los esfuerzos desarrollados y los éxitos parcialmente logrados en las fases de Contenido e Instrumentos no llegan a buen puerto; la Ejecución se ve afectada. Se han identificado -de nuevo ilustrados a través de ejemplos puntualestres grandes Condicionantes y Obstáculos que afectan directamente cada una de las metas señaladas; influyen en la correcta transición interna entre las fases de gobernanza; fortalecen $-y$, en su caso, originan- la situación problemática; y forman parte fundamental de las contradicciones subyacentes.

El primero de esos Condicionantes y Obstáculos toma forma en un poder económico situado por encima de la justicia social. Ante la meta del acceso económico, la centralidad que toma en la sociedad capitalista el valor de cambio -en este caso, de la vivienda- distorsiona el contenido del derecho a la propiedad privada, relegando su valor de uso y su función social a segundo plano. El beneficio esperado en toda promoción residencial afecta la capacidad de disponer de los usos deseados y necesitados (Harvey, 2014), en un modelo inmobiliario orientado a la inversión que busca ingresos controlados - pero continuos- aumentos de precios, ventas constantes y un mercado activo. Esto afecta profundamente diversas escalas y esferas, desbordando el ámbito empresarial, influenciando el desarrollo de políticas públicas y alcanzando el imaginario ciudadano común (Roch, 2009, pp. 182-183). Lo que es una necesidad y debería ser una herramienta de inclusión social pasa a ser un problema (Gondra, 2004, p. 109), haciendo que demanda y necesidad diverjan. La incapacidad de controlar el mercado de un derecho humano como la vivienda y de ofrecer respuestas habitacionales a las personas expulsadas del mismo se debe, en gran parte, a una gran carencia: no admitir que dicho mercado no cumple las leyes económicas básicas, si bien se actúa como si lo hiciera (España, Ministerio de Vivienda, 2010, p. 19; Roch, 2003, p. 121). Todo ello se ve fortalecido por insuficiencias instrumentales, excesos de regulación, generación de paradojas, falta de coordinación institucional, desconocimiento de la realidad social, lecturas parciales, sistemas de ayudas complejos, dificultades financieras o resistencias a cuantificar e identificar viviendas vacías. Hay quien coincide en identificar bajo esta situación razones políticas (Beltrán, 2009, p. 469; Vinuesa, 2013, p. 108) incluyendo varios informes y condenas de la propia ONU; existen ejemplos de estos y otros motivos (Tabla 3).

El segundo gran Obstáculo es una extendida visión conservadora del espacio doméstico. Enfrentada a la meta de la adecuación tipológica, la vivienda colectiva desarrollada en las últimas décadas ha tendido a homogeneizar y simplificar soluciones espaciales, reduciendo la oferta a pequeńas variaciones en torno a una vivienda burguesa jerarquizada y con sesgos de edad, clase y género (Monteys \& 
Fuertes, 2002; Muxí, 2009). Se ha eludido la responsabilidad de reflejar en el espacio doméstico la complejidad y diversidad social, forzando a una gran parte de la población a habitar viviendas diseñadas para otras personas (Guidotti \& Arroyo, 2004). Esto ha sido alimentado por, y a su vez ha influido en, un marco normativo con criterios básicos y rígidos parcialmente anticuados, sin considerar cuestiones más complejas y restringiendo la amplia posibilidad de tipologías residenciales. La definición de programas mínimos no incorpora otras funciones cruciales, como ciertas labores domésticas, actividades económicas o cuidados; las clasificaciones se limitan al número de dormitorios y la superficie total, y las supuestas adaptaciones son variaciones de las anteriores. La existencia de ejemplos que regulan estas cuestiones de manera más avanzada -las condiciones mínimas de habitabilidad de las viviendas de Cataluña incorporan la definición de vivienda flexible y unos criterios de compartimentación más progresistas- evidencia la obsolescencia de ciertas cuestiones del caso vasco, algo que parece haberse asumido y para lo que se está trabajando (García, 2018, p. 9).

TABLA 3 | Ejemplos de anteposición del valor de cambio de la vivienda frente al de uso con efectos en el Área Metropolitana de Bilbao

\begin{tabular}{|l|l|}
\hline \multicolumn{1}{|c|}{ AGENTE } & \multicolumn{1}{c|}{ ACCIóN } \\
\hline Gobierno de España & $\begin{array}{l}\text { Sin ratificar la Carta Social Europea (revisada) de 1996 que afecta al derecho a } \\
\text { la vivienda. }\end{array}$ \\
\hline Gobierno Vasco & $\begin{array}{l}\text { Centrado en las posibles consecuencias en el statu quo y no en sus objetivos } \\
\text { sociales, se opone al proyecto de Ley de Vivienda elaborado desde la oposición } \\
\text { (aprobado en 2015 sin su voto a favor). }\end{array}$ \\
\hline $\begin{array}{l}\text { Partido Popular y } \\
\text { Partido Socialista }\end{array}$ & $\begin{array}{l}\text { En 2017 rechazan una iniciativa del Grupo Unidos Podemos -En Comú } \\
\text { Podem- En Marea para obligar a la Sareb(*) a ceder su parque inmobiliario al } \\
\text { Fondo Social de Viviendas. }\end{array}$ \\
\hline $\begin{array}{l}\text { Pacto Social por la } \\
\text { Vivienda de Euskadi }\end{array}$ & $\begin{array}{l}\text { No se centra tanto en el acceso socioeconómico, como en el crecimiento del } \\
\text { PIB y el empleo (Burón, 2010) y su papel como instrumento de rescate del } \\
\text { sector de la construcción (Eusko Langileen Alkartasuna, 2010). }\end{array}$ \\
\hline Sociedad civil & $\begin{array}{l}\text { Expansión del virus de la especulación, legitimidad de la inversión en vivienda } \\
\text { como garantía económica para el envejecimiento y la idea de riqueza general } \\
\text { (Hernández et al., 1997, p. 12; Naredo, 2015, p. 77). }\end{array}$ \\
\hline Televisión pública vasca & $\begin{array}{l}\text { En 2014 se da como buena noticia la subida de la venta de viviendas, pero se } \\
\text { comunica como negativa la bajada de precios, sin mencionar su naturaleza de } \\
\text { derecho fundamental y alimentando una visión mercantilista. }\end{array}$ \\
\hline
\end{tabular}

Pero el ámbito normativo no justifica por sí solo estas carencias tipológicas. Existe, por un lado, y extendido entre agentes políticos, legisladores, promotores, constructores, diseńadores, agentes comerciales y la propia sociedad demandante, un desconocimiento o falta de interés por el abanico de soluciones posibles. La necesidad urgente de vivienda durante la segunda mitad del siglo xx, rematada por el afianzamiento de un modelo inmobiliario expansivo, hizo que la vivienda racional asentada 
en los CiAM $^{2}$ sea la base común extendida (Amann, 2005, p. v), excluyendo otras formas de convivencia. Esto lleva a señalar la existencia de un camino educativo y divulgativo por recorrer (Montaner et al., 2011, p. 11; Monteys \& Fuertes, 2002, p. 9). También, frecuentemente se hace una interpretación demográfica y sociológica simplista de la problemática, con repercusión en las dimensiones arquitectónica y territorial. Las estrategias y discursos de la planificación residencial en un contexto de disminución del tamaño medio del hogar y de descenso y/o estancamiento poblacional, influidos por un modelo de planificación urbana expansiva centrada en la urbanización y construcción/sustitución de nueva ciudad, se centran en construir nuevas viviendas, argumentando necesitar más para las mismas personas. Esta postura, identificable en agentes públicos y privados (Ayuntamiento de Bilbao, 2015, p. 3; Sarria, 2015), puede, sin embargo, comprenderse como una legitimación para continuar con la producción de viviendas por parte del sistema inmobiliario (Roch, 2003, p. 121), con la única reacción de reducir su superficie. Las limitaciones de esta perspectiva cuantitativa podrían, sin embargo, ser corregidas y completadas mediante un análisis cualitativo (Tabla 4). El mantenimiento del dogma de 'a más hogares, más viviendas nuevas', parece apoyarse en la fallida idea de que el parque actual va a estar eternamente ocupado por parejas heterosexuales con dos o más hijos o hijas. La evolución demográfica -con disminución del peso de estas familias y aumento de la diversidad y cantidad de unidades unipersonales- refleja que este parque se está quedando obsoleto, haciendo urgente su adaptación imaginativa para usar eficazmente dicho patrimonio. Así, en el Амв estos tres fenómenos-normativo, sociocultural y de interpretación sesgada- producen una oferta excluyente y rígida que no encaja con las necesidades habitacionales de muchas personas.

TABLA 4 | Consideraciones cualitativas para corregir la planificación residencial del Área Metropolitana de Bilbao

\begin{tabular}{|l|l|}
\hline PARA QUIÉN & $\begin{array}{l}\text { Análisis de la necesidad: biografías y proyecciones vitales y laborales, hábitos de vida y } \\
\text { culturales, nivel de integración en la comunidad... }\end{array}$ \\
\hline Cómo & $\begin{array}{l}\text { Plantear las viviendas más allá de su cuantificación, su número de dormitorios o su } \\
\text { superficie: usos previstos o posibles y su evolución en el tiempo, niveles de intimidad y } \\
\text { comunidad, disgregación de usos por el edificio, o colectivización de espacios (Monteys } \\
\text { \& Fuertes, 2002). }\end{array}$ \\
\hline DóNDE & $\begin{array}{l}\text { Antes de aumentar por defecto el parque actual, estudiar las características tipológicas y } \\
\text { estado de las viviendas y las edificaciones residenciales con las que la ciudad ya cuenta, } \\
\text { así como el potencial para alterar la estructura de la propiedad sobre la que se apoyan. }\end{array}$ \\
\hline
\end{tabular}

FUENTE: ELABORACIÓN PROPIA

El tercer gran Condicionante es una fuerte inercia urbanizadora heredada. Parte de la reflexión anterior enlaza con la meta del aprovechamiento del parque existente. Frente a esta, el modelo inmobiliario español se fundamenta en la obtención de plusvalías a través de la urbanización de nuevos suelos para la construcción de viviendas, movido por lógicas especulativas ajenas al interés general (Naredo

2 Congrès Internationaux d'Architecture Moderne, organización vigente de 1928 a 1956. 
\& Montiel, 2011, p. 53), y "justificado y aplaudido por la generación de empleo que suponía, alimentando la economía y, sobre todo, las finanzas locales” (Vinuesa, 2013, p. 48). Se trata de un modelo asentado en 1956 -Ley sobre Régimen del Suelo y Ordenación Urbana- que ha "subsistido mucho más allá que la situación de emergencia que lo justificó, dando lugar a efectos contrarios a los que motivaron su alumbramiento" (Tejerina, 2010, p. 30), ya que nació para dar solución a una necesidad urgente de vivienda que no podía ser atendida con medios públicos. Se trasladó así la función pública del urbanismo a manos privadas, a cambio de la garantía de un beneficio económico asegurado. El modelo, vigente en Euskadi con la Ley del Suelo y Urbanismo de 2006, puede considerarse único en el derecho comparado (Tejerina, 2010, p. 29). Sin que esto suponga que la urbanización sea "intrínsecamente perversa", sí parece serlo cuando la dirige el capitalismo especulativo y depredador (Borja, 2011, p. 85), posicionando al servicio de la economía no solo a titulares del suelo, propiedad de vivienda usada y administraciones públicas, sino incluso al derecho urbanístico (Tejedor, 2015, p. 2). La demanda artificial ha alimentado el olvido del patrimonio residencial edificado, impulsada por la caída de los tipos de interés hipotecario, un crecimiento económico mantenido, e incluso el lavado de dinero negro. También lo ha hecho por una alta rentabilidad que limita las posibilidades de intervención y control y que es tanto parcial y excluyente -no incorpora en profundidad cuestiones sociales ni ambientales, tanto próximas como lejanas (Naredo, 2004, p. 15)-, como aparente -la fuerte inversión familiar en la construcción de las últimas décadas dejó de aportar recursos al sistema financiero: se los demandaba para seguir invirtiendo (Inurrieta et al., 2013, p. 17)-.

En el marco de este tercer condicionante, muchas voces han puesto en duda la capacidad del planeamiento espacial tradicional para superar los retos señalados. Algunas lo han hecho con intención de liberalizar la ordenación y ahondar en la pérdida de su capacidad y calidad regulatoria, logrando su desprestigio desde una óptica neoliberal (Roch et al., 2011, p. 6); otras, buscando la recuperación y reinvención de herramientas de planificación integrales. La intervención en la ciudad existente ha estado desincentivada por carecer de herramientas adecuadas y/o de recursos económicos suficientes ante la necesaria viabilidad económica de las operaciones. ${ }^{3}$ Esto ha legitimado otros caminos para la planificación e intervención espacial en la ciudad, como el urbanismo de proyectos, sobre la base de grandes intervenciones parciales, con un importante auge ante la pérdida de confianza en el planeamiento. Sin embargo, como ejemplifica el caso de Abandoibarra -icono paradigmático del 'efecto Bilbao'-, se trata de un modelo que, emulando las lógicas del sector privado y confundiendo arquitectura y urbanismo, tiene tres grandes carencias (Rodríguez, 2002): una enorme dependencia de la viabilidad económica a corto plazo, que la antepone a planteamientos estratégicos que pueden ir variando al son de la primera; una visión simplista y parcial de los procesos de revitalización urbana reducida a cuestiones morfológicas y de viabilidad financiera, que excluye

3 Las nuevas herramientas de ámbito nacional vigentes con el Texto Refundido de la Ley de Suelo y Rehabilitación Urbana de 2015 presentan un contexto más solidario, mayor visión de comunidad y un concepto de viabilidad más integral. Pero la Ley de Suelo y Urbanismo de Euskadi de 2006, con competencia en el AMB, no se ha adaptado aún a la anterior. 
múltiples variables y agentes sociales y económicos; y tratarse de grandes proyectos que, lejos de estar autofinanciados como se busca aparentar, necesitan de una enorme cantidad de recursos públicos que son extraídos de otras áreas o destinos, logrando así un efecto de polarización y exclusión urbana y social.

En el extremo opuesto, existen posturas que reclaman recuperar, con mayor flexibilidad y capacidad de previsión y adaptación, las herramientas de planificación espacial integrales (Borja, 2011; Valenzuela \& Soria, 2012), sin olvidar "la vigencia del urbanismo como disciplina imprescindible no solamente para analizar la realidad urbana, sino para proyectarla y configurarla" (Espuelas, 2007, p. 9). Pero la incorporación progresiva de una visión socialmente más responsable y menos expansiva de la urbanización en los instrumentos de ordenación espacial se queda en ocasiones en mero ejercicio de redacción, sin llegar a la fase ejecutiva. Planteamientos progresistas que ya han sido parcialmente asumidos por los instrumentos y que cuentan con cierto respaldo social, político y académico, se formalizan en un discurso hacia el cambio un tanto superficial y en gran medida incompatible con el modelo de urbanización actual (Tabla 5).

\section{TABLA 5 $\mid$ Conflictos discursivos relacionados con el modelo territorial y urbano en diferentes instrumentos de planificación y ordenación espacial}

\begin{tabular}{|l|l|}
\hline \multicolumn{1}{|c|}{ INSTRUMENTO } & \multicolumn{1}{c|}{ DISCURSO Y CRíTICA } \\
\hline $\begin{array}{l}\text { Planes Generales de } \\
\text { Ordenación Urbana }\end{array}$ & $\begin{array}{l}\text { Carencias para poner en práctica cuestiones urgentes, como la incorpora- } \\
\text { ción de la sostenibilidad en el planeamiento urbano (Espańa, Ministerio } \\
\text { de Vivienda, 2010). }\end{array}$ \\
\hline $\begin{array}{l}\text { Plan Territorial Parcial de } \\
\text { Bilbao Metropolitano }\end{array}$ & $\begin{array}{l}\text { La incorporación de cuestiones como la escasez de suelo, la necesidad de } \\
\text { modelos urbanísticos eficientes, la optimización del patrimonio edificado } \\
\text { o la puesta en carga de las viviendas vacías, conviven con amplias expec- } \\
\text { tativas de nueva urbanización con efectos nocivos sobre el medio rural } \\
\text { (Ainz et al., 2008). }\end{array}$ \\
\hline $\begin{array}{l}\text { Directrices de Ordenación } \\
\text { del Territorio de Euskadi }\end{array}$ & $\begin{array}{l}\text { La incompatibilidad de algunos de sus planteamientos con la hegemó- } \\
\text { nica prioridad del desarrollo económico hace que los primeros se hayan } \\
\text { visto abocados al fracaso o debilitamiento. Entre dichos planteamientos, } \\
\text { la limitación del crecimiento difuso de la vivienda unifamiliar aislada } \\
\text { (Urkidi, 2010, p. 195), o la incorporación del término 'sostenible' de } \\
\text { manera superficial, sin desplazamiento de otras cuestiones incompatibles } \\
\text { (Etxabe, 2012). }\end{array}$ \\
\hline $\begin{array}{l}\text { Pacto Social por la Vivienda } \\
\text { de Euskadi (2010) }\end{array}$ & $\begin{array}{l}\text { Confrontación de discursos sociales y ambientales con el fomento del } \\
\text { empleo y la construcción: "No se puede ser a la vez productivista y } \\
\text { medioambientalista, no se puede apostar por la construcción masiva de } \\
\text { nueva vivienda protegida y a la vez decir que el centro de gravedad de } \\
\text { la política de vivienda debe ser la rehabilitación y regeneración urbana” } \\
\text { (Burón, 2010). }\end{array}$ \\
\hline
\end{tabular}

FUENTE: ELABORACIÓN PROPIA 


\section{Conclusiones}

\section{Validez de la herramienta}

La aplicación de la herramienta propuesta al objeto y caso de estudio seleccionados permite darla por buena. Su uso ha permitido evidenciar, por una parte, la indisolubilidad de los conflictos respecto al modelo predominante, identificables como procesos de diferente intensidad y características prevalentes desde los orígenes de la ciudad industrial (Bastida, 1924; Bilbao, 2016; Muñoz, 2009). Por otra parte, al exponer el papel desarrollado por la diversidad de agentes que participan, o son excluidos, de la gobernanza urbana más allá del Estado -aquí parcialmente mostrada-, pone en evidencia la existencia de un marco altamente contradictorio y desigual. En él, el desarrollo de ciertos debates, políticas e iniciativas de vivienda progresistas se enfrenta a una serie de Condicionantes y Obstáculos que, en muchas ocasiones, aparecen reflejados en los discursos, herramientas o acciones de los agentes que los intentan combatir. Plantear la lucha por la vivienda como una cuestión de bandos enfrentados -si bien existen posiciones en extremos opuestos- es inconducente para abordar con rigor la complejidad de una problemática mucho más diversa. Se corre el peligro de desviar la atención y los esfuerzos hacia objetivos parciales difíciles de lograr, de centrarse en los efectos y no en las causas.

Por otro lado, el trabajo permite apuntar el potencial de esta herramienta para su aplicación y contribución no solo a otros contextos urbanos, sino también a otros retos urbanos. Desde un análisis transversal, facilita la identificación y localización de las contradicciones internas de la sociedad capitalista en procesos de gobernanza urbana al permitir situar, simultáneamente, a los diferentes agentes participantes en distintos momentos y posicionamientos dentro de los mismos. A su vez, esto propicia la identificación de alternativas, sean estas potenciales o en marcha.

\section{Contextualizando las contradicciones en un marco estructural}

En el marco de la herramienta propuesta, puede decirse que se necesitan vías de unión que enlacen Contenido e Instrumentos con una Ejecución final más exitosa y que garanticen la consecución de las Metas iniciales, salvando los Condicionantes y Obstáculos identificados; y que lo logren ya sea generando nuevos puentes, potenciando los existentes o influyendo directamente en el origen de las contradicciones de fondo. Dado que la herramienta de análisis presentada y aplicada busca identificar alternativas transformadoras, y en la medida en que -como se ha señaladoestas surgen por y de las contradicciones existentes, un primer paso será contextualizar los resultados del trabajo en el sistema internamente contradictorio que es el capitalismo. A partir de la identificación de dos contradicciones estructurales del modelo residencial actual en las que enmarcar el análisis realizado, se plantea la existencia en el АмB de dos correspondientes alternativas.

La primera contradicción se refiere a la reproducción local de un desfase común en contextos donde las doctrinas neoliberales se han impuesto (Brenner \& Theodore, 2017, p. 118): no se cumplen, a través del ajuste entre oferta y demanda, las leyes del modelo económico básicas para la autorregulación del mercado en lo que respecta a los precios y características del producto. Hablamos de un modelo en el 
que supuestamente se enmarca el sistema capitalista según una visión neoliberal, y que muchos agentes públicos y privados insisten en tomar como referencia para abordar la problemática del acceso a la vivienda (Roch, 2009). En este ámbito, la rigidez del sistema genera un desfase entre, por un lado, las tipologías y precios de la oferta residencial existente, privada y pública; y por otro, la evolución y diversificación socioeconómica, excluyendo a muchas unidades de convivencia mientras, paralelamente, hay una parte del parque sin vender con precios fuera de su rango de accesibilidad. La alternativa que se deduce es que la presencia de tamaños de hogar medio cada vez menores y con unas pautas de vida y convivencia que difieren en gran medida de las de aquellos para los que fue y es diseńado el parque actual, puede ser precisamente la que active una serie de espacios de oportunidad, ${ }^{4}$ buscando en las características del parque residencial heredado soluciones imaginativas. Estos podrían romper limitaciones tipológicas de las viviendas existentes para transformar la estructura actual de la propiedad y adaptar su oferta espacial a la demanda, a un coste razonable y accesible, a través de la alteración del dogma de que a una vivienda existente le corresponde una unidad de convivencia necesitada.

La segunda contradicción hace referencia a la convivencia conflictiva de dos visiones de la vivienda, que contrapone el valor de uso al de cambio: la visión del acceso a la vivienda como derecho humano universal, aceptada al menos como elemento discursivo; y aquella de la vivienda como objeto de inversión y generación de capital, con un gran peso en la economía. Un desequilibrio en favor del segundo valor -el valor de cambio- niega a muchas personas el valor de uso adecuado de una vivienda, y la diferencia entre ambos puede intensificarse de tal manera que las consecuencias de la contradicción pueden afectar -y de hecho así ha sido- a los sistemas financieros y económicos (Harvey, 2014). En un contexto español, esta contradicción alimenta una concepción errónea del derecho a la propiedad privada, establecido en el artículo 33 de la Constitución. Frecuentemente se concibe ese derecho como individual y personal, cuando su evolución ha llevado a que utilidad individual y función social formen una doble dimensión de la propiedad privada, afectando especialmente a la propiedad inmobiliaria. ${ }^{5}$ La alternativa identificada a esta segunda contradicción, remite a aquellos agentes que busquen y puedan reducir el predominio del valor de cambio a través de planteamientos de planificación, gestión, promoción, intervención, construcción, compra y alquiler de vivienda no necesariamente nuevos, pero sí alternativos al sistema inmobiliario y urbanístico hegemónicos. Se cree que en el Амв este papel puede ser desempeñado -o que lo está siendo en parte ya- por modelos públicos, privados o mixtos minoritarios que, lejos de seguir las inercias heredadas, buscan caminos diferentes para lograr sus metas. Pero la tradición inmobiliaria local no ha dejado prácticamente espacio para

4 Se entienden aquí como 'espacios de oportunidad' situaciones de desajuste con un potencial de mejora demostrable y cuantificable; no como lugares concretos hacia los que dirigir grandes operaciones urbanas económicamente atractivas, sino como fenómeno extendido en el área metropolitana. Se trata, en definitiva, de reivindicar el sentido crítico y responsable del concepto 'oportunidad urbana'; recuperarlo de un discurso expansionista que solo atiende a variables de acumulación económica.

5 Disponible en: http://www.congreso.es/consti/constitucion/indice/sinopsis/sinopsis.jsp?art=33\&tipo=2. 
el desarrollo de este tipo de iniciativas, frecuentes sin embargo en países cercanos (Rodríguez, 2001), las cuales requieren un necesario control público y social, así como un fuerte compromiso, en la medida en que afectan un derecho humano básico (Alguacil, 1995).

De la contradicción a la alternativa: una hipótesis de partida

El espíritu constructivo y socialmente transformador que subyace a la presente investigación alimenta el objetivo de desarrollar un trabajo empírico. Enlazando y complementando mutuamente sendas alternativas, se plantea que los mencionados agentes podrían empoderarse si aprovechan el potencial de los espacios de oportunidad identificados. Así, los resultados permiten formular una hipótesis en tres pasos: i) en el АMв puede darse un uso más eficaz al parque residencial heredado debido a ciertos espacios de oportunidad existentes por desajustes económicos y espaciales entre la oferta y la demanda, lo que permitiría transformar tipológicamente dicho parque, mejorar el acceso económico y alterar tanto la estructura de la propiedad como las correspondencias habituales entre unidades de convivencia y viviendas existentes; ii) existen en la región, aunque con baja presencia, agentes alternativos -desde programas de gestión públicos a cooperativas privadas, pasando por agentes inmobiliarios éticos o empresas privadas orientadas a la consultoría urbana social- actuando a diferentes escalas que intervienen en el acceso a la vivienda y que buscan avanzar hacia las metas aquí marcadas, luchando contra la situación problemática identificada; iii) estos agentes, dentro del marco normativo y el contexto actual, están aprovechando, o tienen potencial para hacerlo, los espacios de oportunidad mencionados para alcanzar dichas metas y salvar, al menos parcialmente, los Condicionantes y Obstáculos identificados (Figura 2).

FIgURA 2 | Complementariedad de las alternativas identificadas, a partir de las dos contradicciones estructurales, con el esquema propuesto de generación de contradicciones en procesos de gobernanza urbana, para el caso de la vivienda en el Área Metropolitana de Bilbao

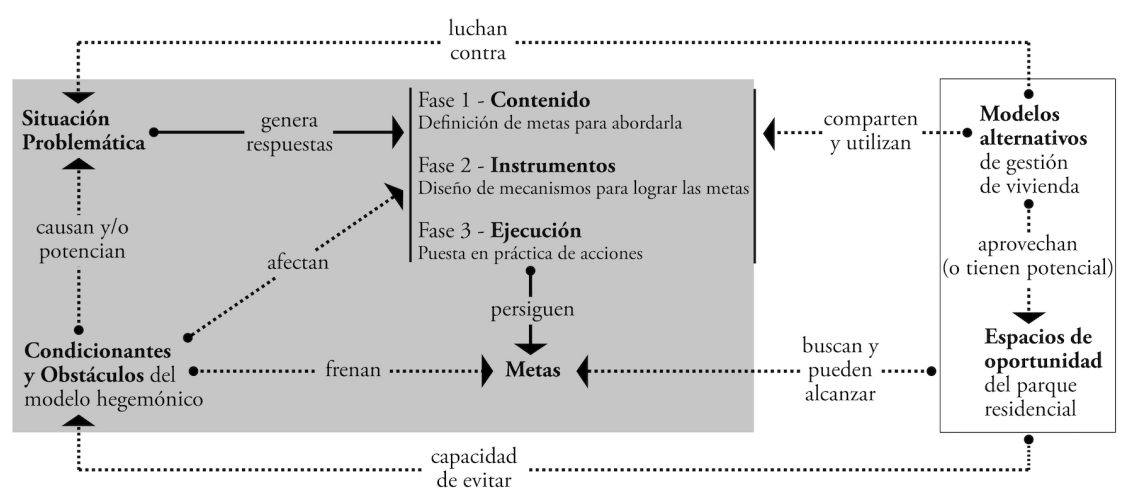

FUENTE: ELABORACIÓN PROPIA 
Esta formulación forma parte de una investigación más amplia desarrollada en el marco de una tesis doctoral, cuya introducción, justificación y marco teórico se ha sintetizado en este artículo. Los resultados finales obtenidos, que se presentarán en futuras publicaciones, han confirmado que de la capacidad que la sociedad en su conjunto -como generadora y a la vez destinataria final de este derecho- llegue a desarrollar para asumir, comprender y afrontar sus contradicciones, así como para aprovechar de manera colectiva las alternativas que de estas surgen, dependerá gran parte del éxito de transformación del modelo residencial aquí analizado y su empoderamiento como agente demandante de vivienda.

\section{Referencias bibliográficas}

Ainz, M. J., González, M. J. \& Moro, I. (2008). Sostenibilidad de las propuestas de suelo para nuevos desarrollos residenciales en la planificación territorial de Bizkaia. Forum de Sostenibilidad, 2, 111-125. https://addi.ehu.es/handle/10810/11229

Alguacil, J. (1995). Veinticinco tesis sobre la complejidad del concepto de lo social en las intervenciones de vivienda pública. En L. Cortés (Ed.), Pensar la vivienda (pp. 70-90). Talasa.

Alokabide. (2014). Memoria 2014. [Alokabide: sociedad pública de alquiler social dependiente del Gobierno Vasco]. https://bit.ly/2TXIgI9

Amann, A. (2005). El espacio doméstico: La mujer y la casa. Tesis Doctoral, Escuela Técnica Superior de Arquitectura, Universidad Politécnica de Madrid. http://oa.upm.es/164/

Antolín, J. E., Fernández, J. M. \& Lorente, E. (2010). Estrategias de regeneración urbana y segregación residencial en Bilbao: Apariencias y realidades. Ciudad y territorio: Estudios territoriales, 42(163), 67-82. https://recyt.fecyt.es/index.php/CyTET/article/ view/75976

Ávila, J. L. (1998). El suelo como elemento ambiental: Perspectiva territorial y urbanística. Universidad de Deusto.

Ayuntamiento de Bilbao. (2015). Revisión del Plan General de Ordenación Urbana. Resumen global de las conclusiones del diagnóstico participado desde la óptica urbanistica. Ayuntamiento de Bilbao. Área de Planificación Urbana. https://bit.ly/32lGVzd

Azpiri, A. (1997). El aumento de la superficie urbanizable ¿conduce a un descenso de los precios del suelo? Una reflexión histórica sobre Bilbao en el entorno del año 1900. Ciudady Territorio: Estudios territoriales, 29(111), 127-142. https://recyt.fecyt.es/index.php/ CyTET/article/view/84381/62265

Bastida, R. (1924). El problema de la vivienda en Vizcaya. Arquitectura: órgano de la Sociedad Central de Arquitectos, (64), 221-222. https://bit.ly/3p84gyq

Beltrán, M. (2009). Las legislaciones de vivienda social. Ciudad y Territorio: Estudios territoriales, 41(161-162), 453-472. https://185.79.129.203/index.php/CyTET/ article/view/75943

Bilbao, L. (2016). Debates y controversias en torno a la vivienda en Bilbao (1965-1975). Bidebarrieta, O(26), 98-119. https://ojs.ehu.eus/index.php/Bidebarrieta/article/view/ 18802 
Borja, J. (2011). ¿Un cambio de ciclo o un cambio de época? Sietelíneas para la reflexión y la acción. Urban, (01), 83-90. https://dialnet.unirioja.es/servlet/articulo?codigo=3762443

Brenner, N. (2017). ¿Qué es la teoría urbana crítica? En Á. Sevilla (Ed.), Neil Brenner: Teoría urbana crítica y politicas de escala (pp. 234-254). Icaria.

Brenner, N. \& Theodore, N. (2017). Las ciudades y las geografías del "neoliberalismo realmente existente”. En Á. Sevilla (Ed.), Neil Brenner: Teoría urbana crítica y politicas de escala (pp. 113-159). Icaria.

Burón, J. (2010, junio 19). Pacto por la vivienda en Euskadi: Rescate del mercado, el pIB y el empleo [Blog]. Leolo. https://bit.ly/3n46MDF

Comisión Europea. (1999). Estrategia Territorial Europea. Hacia un desarrollo equilibrado y sostenible del territorio de la Unión Europea. Oficina de Publicaciones Oficiales de las Comunidades Europeas. https://ec.europa.eu/regional_policy/sources/docoffic/ official/reports/pdf/sum_es.pdf

Consejo de la Juventud de España. (2016). Observatorio de emancipación. País Vasco. Primer semestre de 2015. http://www.cje.org/es/publicaciones/novedades/observatorio-deemancipacion-n-10-primer-semestre-2015/

Engels, F. (1974). El problema de la vivienda y las grandes ciudades. Gustavo Gili.

Engels, F. (2006). Contribución al problema de la vivienda. Fundación Federico Engels.

España, Ministerio de Vivienda. (2010). Libro Blanco de la Sostenibilidad en el Planeamiento Urbanistico Español. Centro de Publicaciones, Ministerio de Fomento. http://habitat. aq.upm.es/lbl/a-lbl.es.pdf

Espuelas, F. (2007). Presentación. En J. M. García-Pablos (Ed.), Perspectivas urbanas: Residencia, ciudad, territorio. Editorial Fundación COAM.

Etxabe, I. (2012). La necesidad de un cambio de modelo de desarrollo y su reflejo en la Ordenación Territorial (El caso de las Directrices de Ordenación del Territorio del País Vasco). Territorios en formación, O(2), 21-36. http://polired.upm.es/index.php/ territoriosenformacion/article/view/1771

Etxezarreta, A. (2010). Vivienda vacía e intervención pública en la Comunidad Autónoma del País Vasco en el contexto europeo. Revista de Economía Crítica, 10(Semi monográfico: Crisis del modelo agroalimentario y alternativas), 4-26. http://www. revistaeconomiacritica.org/sites/default/files/revistas/n10/1.pdf

European Environment Agency. (2006). Urban sprawl in Europe - The ignored challenge. Office for Official Publications of the European Communities.

Euskadi Lagunkoia. (2017). Guía práctica para la implantación y uso en municipios. Gobierno Vasco. Departamento de Empleo y Políticas Sociales. https://www.euskadilagunkoia. net/es/euskadi-lagunkoia/guia-pratica

Eusko Langileen Alkartasuna. (2010). Pacto Social por la Vivienda en Euskadi. En Gabinete de Estudios de ELA, Estudios, 22 (pp. 34-39). https://bit.ly/32nmUs9

Fariña, J. (2004). Sostenibilidad y racionalidad de los procesos de urbanización. Cuadernos de Investigación Urbanistica, (42), 7-12. https://dialnet.unirioja.es/ejemplar/121561

Fumadó, J. L. \& Paricio, I. (1999). El tendido de las instalaciones. Bisagra.

Gaja, F. (2003). El suelo como excusa: El desarrollismo rampante. Papeles de la Fundación de Investigaciones Marxistas - Revista de Investigación Marxista, 20, monográfico Suelo y Vivienda, 1er. semestre, pp. 55-66. Reproducido en Boletin $C F+S$, (29/30) (2005). http://polired.upm.es/index.php/boletincfs/article/view/2168 
García, P. (2018). Debemos de inculcar una cultura del mantenimiento de lo cotidiano. Bilbao, (338), p. 9. https://bit.ly/36id0cG

Gobierno Vasco. (2011). Ecoeuskadi. Estrategia de desarrollo sostenible de Euskadi 2020. https:// bit.ly/311dvhc

Gobierno Vasco. (2013). Plan Director de Vivienda 2013-2016. Fase I: Información y diagnóstico. https://bit.ly/367ands

Gobierno Vasco. (2017). Plan de Vivienda 2018-2020. Informe diagnóstico. Informe final. https://bit.ly/36idYFQ

Gondra, G. (2004). Euskadiko Etxebizitzen-Kooperatibak (iruzkinak). Revista Vasca de Economía Social - Gizarte Ekonomia Euskal Aldizkaria, O(0), 107-138. https://dialnet. unirioja.es/servlet/articulo?codigo $=1302539$

González, M. J. (2013). El derecho a la vivienda. Reflexiones en un contexto socioeconómico complejo. Dykinson.

Guidotti, E. \& Arroyo, C. (2004). Formas de vida: Ideas sobre vivienda social y vivienda de protección oficial. Croquis, 119, 176-181.

Habraken, N. J. (1972). Supports: An alternative to mass housing. The Architectural Press.

Harvey, D. (2014). Diecisiete contradicciones y el fin del capitalismo. Traficantes de Sueńos.

Hernández, A., Alguacil, J., Medina, M. \& Moreno, C. (1997). La ciudad de los ciudadanos. Ministerio de Fomento, España. Versión digital: http://habitat.aq.upm.es/aciudad/

Inurrieta, A., Irigoien, E., Murgui, N. \& Naredo, J. M. (2013). Qué hacemos por la vivienda. Akal.

Jessop, B. (2017). El Estado. Pasado, presente y futuro. Catarata.

Leal, J. (1995). La cuestión de la vivienda o la vivienda como problema social. En L. Cortés (Ed.), Pensar la vivienda (pp. 17-30). Talasa.

Lefebvre, H. (2013). La producción del espacio. Capitán Swing.

Logan, J. R. \& Molotch, H. L. (1987). Urban fortunes: The political economy of place. University of California Press.

Madden, D. \& Marcuse, P. (2018). En defensa de la vivienda. Capitán Swing.

Marcuse, H. (1985). El hombre unidimensional: Ensayo sobre la ideología de la sociedad industrial avanzada. Planeta-De Agostini.

Montaner, J. M., Muxí, Z. \& Falagán, D. H. (2011). Herramientas para habitar el presente. La vivienda del siglo XXI. Máster Laboratorio de la Vivienda del Siglo XxI. https://bit. ly/3kcdqGe

Monteys, X. \& Fuertes, P. (2002). Casa collage: Un ensayo sobre la arquitectura de la casa. Gustavo Gili.

Muñoz, F. J. (2009). Habitar periferias urbanas: la gestión de la vivienda en los márgenes de la ciudad en Bilbao. Zainak. Cuadernos de Antropologia-Etnografia, 32, 773-803. https:// core.ac.uk/download/pdf/11503629.pdf

Muxí, Z. (2009). Recomanacions per a un habitatge no jeràrquic ni androcentric. Institut Català de les Dones.

Naciones Unidas. (2008). Promoción y protección de todos los derechos humanos, civiles, politicos, económicos, sociales y culturales incluido el derecho al desarrollo. Informe del Relator Especial sobre una vivienda adecuada como elemento integrante del derecho a un nivel de vida adecuado, Sr. Miloon Kothari. Adición: Misión a España. https://www. refworld.org.es/docid/47c7d4b82.html 
Naredo, J. M. (1994). El funcionamiento de las ciudades y su incidencia en el territorio. Ciudad y Territorio: Estudios territoriales, 2(100-101), 233-249. https://recyt.fecyt.es/ index.php/CyTET/article/view/83944

Naredo, J. M. (2004). Diagnóstico sobre la sostenibilidad: La especie humana como patología terrestre. Archipiélago. Cuadernos de crítica de la cultura, 62, 13-23.

Naredo, J. M. (2015). Un episodio relevante: La burbuja especulativa y la crisis inmobiliaria en perspectiva. Cuadernos de Investigación Urbanistica, $O(100)$, 77-82. https://dx.doi. org/10.20868/ciur.2015.100.3168

Naredo, J. M. \& Montiel, A. (2011). El modelo inmobiliario español y su culminación en el caso valenciano. Icaria.

Observatorio Vasco de la Vivienda. (2015). Indicadores del mercado de la vivienda en la C.A. de Euskadi ( $4^{\circ}$ trimestre 2015).

Observatorio Vasco de la Vivienda. (2017a). Indicadores del mercado de la vivienda en la C.A. de Euskadi ( $3^{\circ}$ trimestre 2017).

Observatorio Vasco de la Vivienda. (2017b). Los efectos de la crisis: La respuesta de la política de vivienda a los desahucios y el sobre-endeudamiento.

onU-Hábitat. (2016). Reporte ciudades del mundo 2016: Urbanización y desarrollo. Futuros emergentes. ONU-Hábitat. http://70.35.196.242/onuhabitatmexico/ Reportedelasciudades2016.pdf

Open Data Euskadi. (2017). Indicadores municipales de sostenibilidad: Unidades convivenciales perceptoras de Ayudas de Emergencia Social (\%o habitantes). https://bit.ly/315lxWx

Orive, L. A. (2006). Relaciones ciudad-naturaleza en Vitoria-Gasteiz. Boletín $C F+S$, (38/39). http://habitat.aq.upm.es/boletin/n38/aland.html

Paricio, I. \& Sust, X. (2000). La vivienda contemporánea: Programa y tecnología. Institut de Tecnologia de la Construcció de Catalunya - ITeC.

Parlamento Europeo. (2013). Informe sobre la vivienda social en Europa. https://bit.ly/2IbwQ12

Peremiquel, F., Font, A. \& Salvà, I. (2000). Vivienda: Innovación y proyecto. "Necesidades, nuevas tecnologias y estrategias proyectuales". Col-legi d'Arquitectes de Catalunya.

Pisarello, G. (2003). Vivienda para todos: Un derecho en (de)construcción, el derecho a una vivienda digna y adecuada como derecho exigible. Icaria.

Roch, F. (2003). La ciudad inmobiliaria y el precio de la vivienda. Papeles de la Fundación de Investigaciones Marxistas, 20(2a época), 115-129.

Roch, F. (2009). Morfología, deterioro urbano y precio de la vivienda en Madrid. Ciudades: Revista del Instituto Universitario de Urbanistica de la Universidad de Valladolid, (12), 171-196. https://doi.org/10.24197/ciudades.12.2009.171-196

Roch, F., Fernández, J. M. \& Sevilla, Á. (2011). Nueva época, viejos conflictos: Ciudades y teorías urbanas en la encrucijada. Urban, 01, 3-12. http://polired.upm.es/index.php/ urban/article/view/403/1759

Rodríguez, A. (2002). Reinventar la ciudad: Milagros y espejismos de la revitalización urbana en Bilbao. Lan Harremanak, (6), 69-108. https://ojs.ehu.eus/index.php/Lan_ Harremanak/article/view/5848

Rodríguez, A., Martínez, E. \& Guenaga, G. (2001). Uneven Redevelopment. New urban policies and socio-spatial fragmentation in Metropolitan Bilbao. European Urban and Regional Studies, 8(2), 161-178. https://doi.org/10.1177\%2F096977640100800206 
Rodríguez, J. (2001). Estructura y cambios del parque residencial de la C.A. de Euskadi. Eustat. Instituto Vasco de Estadística.

Sarria, A. (2015, junio 16). Necesidad de vivienda y cuantificación residencial [Blog]. Estudio $K$. http://estudiok.es/necesidad-de-vivienda/

Smith, N. (2015). Nuevo globalismo y nuevo urbanismo. La gentrificación como estrategia urbana global. En Observatorio Metropolitano de Madrid (Ed.), El mercado contra la ciudad. Globalización, gentrificación y políticas urbanas (pp. 245-270). Traficantes de Sueños.

Swyngedouw, E. (2005). Governance innovation and the citizen: The janus face of governance-beyond-the-State. Urban Studies, 42(11), 1991-2006. https://doi. org/10.1080\%2F00420980500279869

Swyngedouw, E., Moulaert, F. \& Rodríguez, A. (2002). Neoliberal urbanization in Europe: Large-scale urban development projects and the New Urban Policy. Antipode. A Radical Journal of Geography, 34(3), 542-577. https://doi.org/10.1111/1467-8330.00254

Tejedor, J. (2015). Nuevo paradigma normativo sobre la ciudad: Retornando a la ciudad tradicional. Informes de la construcción, 67 Extra 1. https://bit.ly/3mX5Dhi

Tejerina, J. I. (2010). Modelos urbanísticos. En J. I. Tejerina, Manual de ejecución urbanística (pp. 25-37). Instituto Vasco de Administraciones Públicas, Bilbao.

Turner, J. F. C. (1977). Vivienda, todo el poder para los usuarios: Hacia la economía en la construcción del entorno. Blume.

Urkidi, P. (2010). Las políticas de ordenación del territorio en la Comunidad Autónoma Vasca, 1990-2006. Boletín de la Asociación de Geógrafos Españoles, (52), 189-212. https:// dialnet.unirioja.es/servlet/articulo?codigo=3198639

Valenzuela, L. M. \& Soria, J. A. (2012). La incidencia de la planificación: Propuesta de evaluación aplicada al desarrollo metropolitano. Urban, (03), 81-104. http://polired. upm.es/index.php/urban/article/view/1809

Vázquez, M. (2010). El territorio desde la perspectiva ecológica. Boletín $C F+S$, (42/43). http:// polired.upm.es/index.php/boletincfs/article/view/2801

Vegara, A. (1999). Los SmartLands. El milagro de Bilbao. Ciudades: Revista del Instituto Universitario de Urbanistica de la Universidad de Valladolid, (5), 21-42. https://doi. org/10.24197/ciudades.05.1999.21-42

Vicario, L. \& Rodríguez, A. (2005). Innovación, competitividad y regeneración urbana: Los espacios retóricos de la "ciudad creativa" en el nuevo Bilbao. Ekonomiaz: Revista Vasca de Economía, (58), 262-295. https://dialnet.unirioja.es/servlet/articulo?codigo=2008997

Vidarte, J. I. (2007). Nuevas infraestructuras culturales como factor de renovación urbanística, revitalización social y regeneración económica. El Museo Guggenheim Bilbao. Museo: Revista de la Asociación Profesional de Museólogos de España, (12), 99-108. https:// dialnet.unirioja.es/servlet/articulo?codigo $=2505594$

Vinuesa, J. (2013). El festín de la vivienda. Auge y caída del negocio inmobiliario en España. Díaz $\&$ Pons.

Zubero, I. (2012). "Primero tomaremos Manhattan": Regeneración urbana, insurgencias ciudadanas y emergencias culturales en Zorrotzaurre (Bilbao). Urban, (03), 65-80. http://polired.upm.es/index.php/urban/article/view/1808 